\title{
Cutting-edge effective endoscopic technique to remove scarred polyps
}

Scarred polyps, especially those larger than $20 \mathrm{~mm}$, are challenging to resect using conventional endoscopic mucosal and submucosal resection techniques. The EndoRotor (Interscope, Inc.) is a novel automated mechanical endoscopic resection system designed for use in the gastrointestinal tract for tissue dissection and resection [1]. Its use has been demonstrated to be a safe and effective technique in the management of scarred polyps [2].

We describe a case of an 80-year-old woman with a large recurrent polyp in the rectum. Three previous attempts at eradication had been made using endoscopic mucosal resection (EMR) plus argon plasma coagulation (APC).

Surveillance colonoscopy performed 1 year after the last EMR plus APC showed, $3 \mathrm{~cm}$ above the anal verge, a scarred granular laterally spreading tumor (LST-G) with a diameter of $40 \mathrm{~mm}$, hemicircumferential and with an adenomatous pit pattern (Kudo IIIL) on evaluation with digital chromoendoscopy (BLI/LCI) ( Fig. 1).

Because of the scar tissue, which represented $60 \%$ of the lesion and made mucosal or submucosal resection impossible, we decided to treat the patient with the EndoRotor technique. After circumferential marking with APC and submucosal injection ( $>$ Video 1 , steps 1 and 2 ), the EndoRotor catheter was inserted into the instrument channel and the solid black line at the tip of the catheter was positioned directly above the lesion. Using the EndoRotor, complete resection was achieved without bleeding or other intraoperative or postoperative adverse events ( Fig. 2, \Fig.3; \Video 1, step 3). PuraStat, a self-assembling peptide used for hemostasis, was applied prophylactically over the resection base at the end of procedure ( $\$$ Fig. 4; Video 1, steps 4 and 5). The patient was discharged the same day.

The resected tissue fragments were collected and histological assessment

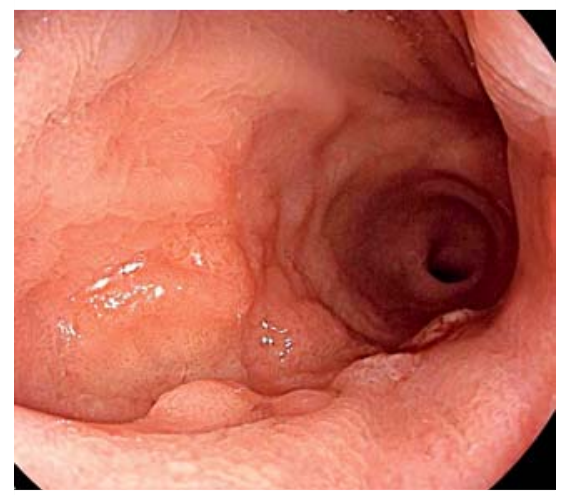

Fig. 1 Scarred granular laterally spreading tumor (LST-G) in rectum, diameter $40 \mathrm{~mm}$, hemicircumferential, and with an adenomatous pit pattern (Kudo IIIL).

identified a tubulovillous adenoma with low-grade dysplasia. The subsequent 6-month endoscopic follow-up did not show any recurrence or stricture ( $\mathbf{F i g}$. 5; - Video 1, step 6).

This case demonstrates the use of a novel nonthermal device, EndoRotor, as a safe and effective technique in challenging management of scarred polyps.

Endoscopy_UCTN_Code_TTT_1AQ_2AJ FB

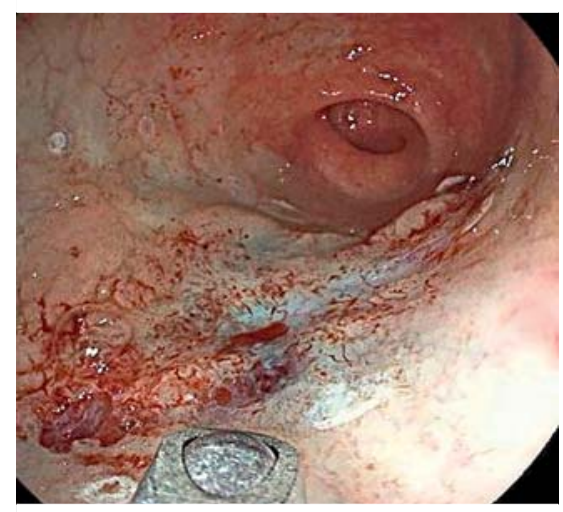

Fig. 2 Resection of scarred polyp with the EndoRotor.

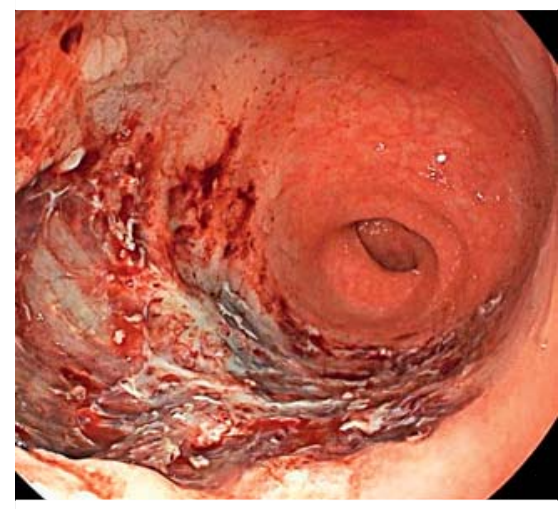

Fig. 3 Resection complete.

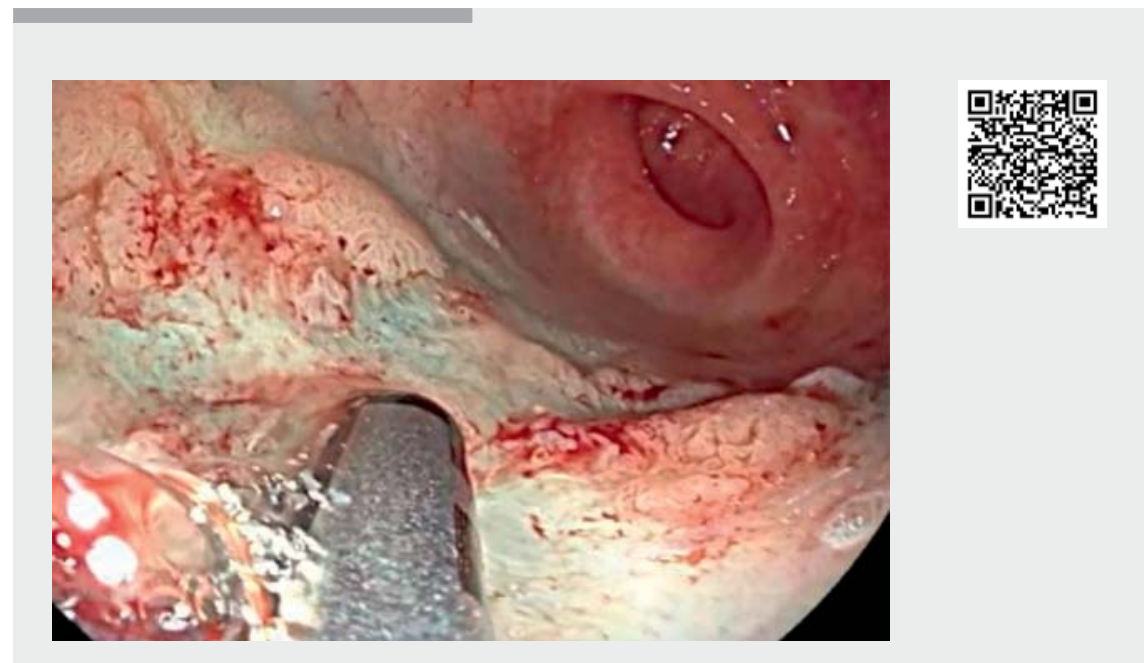

Video 1 Endoscopic resection of a rectal scarred LST-G, hemicircumferential and with a diameter of $40 \mathrm{~mm}$, using the EndoRotor. 


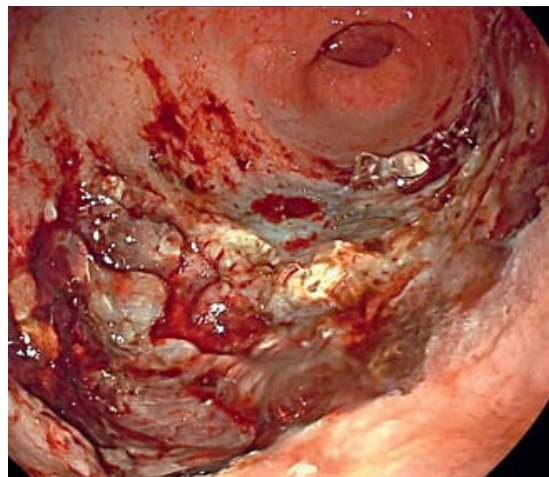

- Fig.4 Application of PuraStat over the resection base.

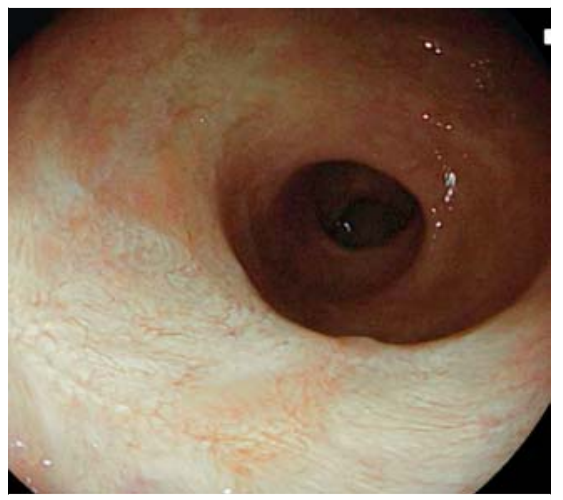

Fig. 5 Endoscopic follow-up 6 months later.
The authors declare that they have no conflict of interest.

The authors

Gaia Pellegatta ${ }^{1}$, Benedetto Mangiavillano², Roberta Maselli ${ }^{1}$, Pradeep Bhandari ${ }^{3}$, Milena Di Leo ${ }^{1}$, Matteo Badalamenti ${ }^{1}$, Alessandro Repici $^{1}$

1 Digestive Endoscopy Unit, Division of Gastroenterology, Humanitas Research Hospital, Humanitas University, Rozzano (MI), Italy

2 Gastrointestinal Endoscopy Unit, Humanitas Mater Domini, Castellanza, Varese, Italy

3 Queen Alexandra Hospital, Portsmouth, Hampshire, United Kingdom

\section{Corresponding author}

\section{Gaia Pellegatta, MD}

Digestive Endoscopy Unit, Division of Gastroenterology, Humanitas Research Hospital, Via Manzoni 56, 20089 Rozzano (Milano), Italy

gaia.pellegatta@humanitas.it

\section{References}

[1] Hollerbach S, Wellmann A, Meier P et al. The EndoRotor: endoscopic mucosal resection system for non-thermal and rapid removal of esophageal, gastric, and colonic lesions: initial experience in live animals. Endosc Int Open 2016; 4: E475-E479

[2] Kandiah K, Subramaniam S, Chedgy F et al. A novel non-thermal resection tool in endoscopic management of scarred polyps. Endosc Int Open 2019; 7: E974-E978

\section{Bibliography}

DOI https://doi.org/10.1055/a-1130-6041

Published online: 27.3.2020

Endoscopy 2020; 52: E362-E363

(c) Georg Thieme Verlag KG

Stuttgart · New York

ISSN 0013-726X

\section{ENDOSCOPY E-VIDEOS}

https://eref.thieme.de/e-videos

$\square$ Endoscopy E-Videos is a free access online section, reporting 靣转: on interesting cases and new techniques in gastroenterological endoscopy. All papers include a high quality video and all contributions are freely accessible online.

This section has its own submission website at https://mc.manuscriptcentral.com/e-videos 